\title{
Empowerment through Technology: Gender Dimensions of Social Capital Build-Up in Maharashtra, India
}

\author{
Ravula Padmaja \\ and \\ Cynthia Bantilan, \\ International Crops Research Institute for the Semi-Arid Tropics \\ (ICRISAT)
}

International Research Workshop on 'Gender and Collective Action'

October 17-21, 2005• Chiang Mai, Thailand

The CGIAR Systemwide Program on Collective Action and Property Rights (CAPRi) is an initiative of the 15 centers that belong to the Consultative Group on International Agricultural Research. The initiative promotes comparative research on the role played by property rights and collective action institutions in shaping the efficiency, sustainability, and equity of natural resource systems. CAPRi's Secretariat is hosted by the International Food Policy Research Institute's (IFPRI) Environment and Production Technology Division (www.ifpri.org).

CAPRi Working Papers contain preliminary material and research results and are circulated prior to a full peer review in order to stimulate discussion and critical comment. It is expected that most Working Papers will eventually be published in some other form, and that their content may also be revised. http://dx.doi.org/10.2499/CAPRiWP63

Copyright @ February 27, 2007 International Food Policy Research Institute. All rights reserved. Sections of this material may be reproduced for personal and not-for-profit use without the express written permission of but with acknowledgment to IFPRI. To reproduce the material contained herein for profit or commercial use requires express written permission. To obtain permission to reprint, contact the IFPRI Communications Division at ifpri-copyright@cgiar.org.

CGIAR Systemwide Program on Collective Action and Property Rights (CAPRi) c/o INTERNATIONAL FOOD POLICY RESEARCH INSTITUTE 


\section{ACKNOWLEDGMENTS}

This publication is a result of a collaborative research project entitled," Gender dimensions in social capital build-up and technology adoption" funded by FAO-RAP (Food and Agricultural Organization of the United Nations, Regional Office for Asia and Pacific).

The authors acknowledge the excellent contributions and consultations of D Parthasarathy in planning, and conceptualization of the study. The assistance of V K Chopde in conducting FGMs during fieldwork is greatly appreciated. Thanks are due to BVJ Gandhi and Neetu Choudhary for their work in the field. We also thank Revathi Balakrishnan of FAO-RAP for her advice and support to these diverse ideas. 


\begin{abstract}
This paper explores how and to what extent women and men have benefited from the build-up of social capital in technology uptake, and the role of women in this process. Using a case study on Groundnut Production Technology (GPT) in Maharashtra, India, a systematic documentation of the process by which farmers - both men and women - as well as the whole community became empowered through the build-up of social capital is presented. The focus of the paper is on collective action as a mechanism to stimulate gender-equitable change processes.

Our evidence suggests that the technology uptake process was enhanced with the build up of social capital, whereby men and women from all class and caste groups came together for improving their livelihoods. Collective action was enhanced with the increased involvement and participation of women. Strong kinship ties were developed among diverse classes all over the village including landless tribal women, who formed the major labor force for this technology.

The paper concludes that social networks played a crucial mediating role in the process of technology uptake. The build-up of social capital played an important role in influencing impacts from the technology because of the ways in which social networks and social relationships facilitated technology dissemination. Gender relations played a significant role in mediating the translation of economic benefits into well being of the individual, the family and community. Finally, it is suggested that further insights into the role of social networks and power relations in the village may be examined in greater detail by establishing the village network architecture, especially marginalized groups.
\end{abstract}

Keywords: social capital build-up, gender, impact, social networks, empowerment 


\section{TABLE OF CONTENTS}

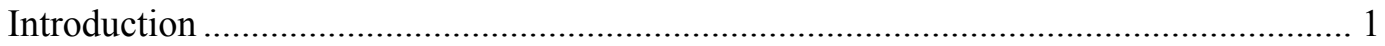

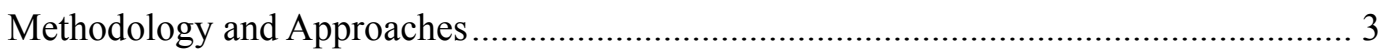

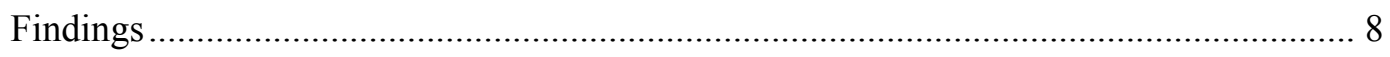

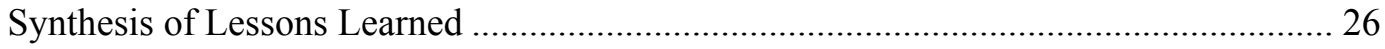

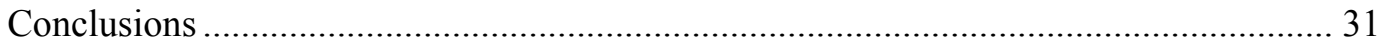

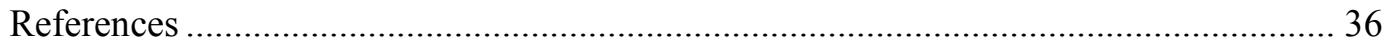




\title{
Empowerment through Technology: Gender Dimensions of Social Capital Build-Up in Maharashtra, India
}

\author{
Ravula Padmaja ${ }^{1}$ and Cynthia Bantilan ${ }^{2}$
}

\section{INTRODUCTION}

Agricultural research during the past 30 years has been successful in boosting productivity and providing enough food to feed the world. However, problems of poverty, food insecurity, and natural resource degradation persist. Producers in agricultural communities, both men and women, are confronted by production challenges associated with changing populations, a degrading natural resource base, new technologies and accelerated global economic integration (Asian Productivity Organization 2002). Hence, recent research has moved beyond physical and human capital to explore the significance of 'social capital' and its effects on development outcomes.

Social capital refers to the norms and networks that facilitate collective action (Woolcock 2001), or the ability of men and women farmers to develop and use various kinds of social networks and the resources that become available thereof. Social capital can also be referred to as the voluntary action taken by a group to achieve common interests. Within this context, there is currently considerable interest in the role of social capital in society, especially in its potential to foster sustainable development. In keeping with the primacy of gender in socio-economic development issues, the gender-related dimension of social capital is an emerging theme for research. The literature identifies the family as the main source of

\footnotetext{
${ }^{1}$ Senior Scientific Officer, Institutions, Markets, Policy and Impacts, International Crops Research Institute for the Semi-Arid Tropics (ICRISAT), Patanchery 502 324, Andhra Pradesh, India, r.padmaja@cgiar.org

${ }^{2}$ Global Theme Leader on Institutions, Markets, Policy and Impacts, International Crops Research Institute for the Semi-Arid Tropics (ICRISAT), Patanchery 502 324, Andhra Pradesh, India, c.bantilan@cgiar.org
} 
economic and social welfare and thus as the first building block in the generation of social capital for the larger society. Women as primary caregivers are seen as playing a critical role in the process. The social capital thus generated is an important means by which women gain access to resources and economic opportunities helping them to find an exit path out of poverty.

The International Crops Research Institute for the Semi-Arid Tropics (ICRISAT), with a mission to improve the well-being of the poor in the semi-arid tropics (SAT) through agricultural research for impact, has a commitment to equity in its pursuit of poverty alleviation. Recognizing that the gender-related benefits of particular technologies would differ among diverse groups, ICRISAT uses its comparative advantage in the identification of globally applicable principles and methodologies in addressing the achievement of equity goals. For example, a gender analysis of the impacts from the improved groundnut production technology introduced in Maharashtra, India during the late 1980's led to the conclusion that gender is a key variable in relation to labor activity pattern and time use, decision-making behavior concerning resource use and crop product utilization and perceptions of needs of new technology development (Kolli and Bantilan 1997). Information of this kind provides evidence that gender makes a difference in economic circumstances.

This paper explores how and to what extent women and men have benefited from the social capital build-up in technology uptake, and more specifically the role of women in this process. Illustrating the learning processes experienced at ICRISAT vis-à-vis impact studies of a specific NRM technological innovation generated through research on the poor in waterlimited environments of the semi arid-tropics (SAT), the paper focuses on collective action as a mechanism to stimulate gender-equitable change processes. It provides an understanding of 
the role of social capital in facilitating access to information, credit, institutional support, common property resources, and community support (i.e. issues of exclusion). The importance of the changing dynamics of social capital in such situations is likely to yield insights for better understanding the processes of technology uptake and diffusion by gender.

\section{METHODOLOGY AND APPROACHES}

The following section provides the details of the technology and the different approaches adopted to assess the impact of the technology, featuring the various phases of learning in terms of new impact dimensions and methods.

\section{Groundnut Production Technology (GPT)}

Groundnut Production Technology (GPT) is a package of practices for dryland cultivation of groundnuts. It is essentially a natural resource management (NRM) innovation. The GPT was specifically developed for cultivation of groundnuts in dry areas, especially to promote cultivation in summer using an improved package of practices which include improved cultivars, as well as soil, water, and nutrient management options (See Appendix 1 for more details). The GPT encompasses several components related to soil, nutrient, crop, water, and pest management. The components of the GPT can broadly be divided into:

- land management: preparation of raised-bed and furrows (BBF) for groundnut production;

- nutrient management: efficient application of macro- and micro-nutrients;

- improved varieties: high-yielding variety seeds, seed rate and seed dressing/ treatment;

- insect and pest management: effective control of insects, diseases, and weeds; and 
- water management: use of sprinkler sets to improve efficiency of irrigation.

The GPT was introduced in Umra village of Nanded district in Maharashtra, India (along with other villages in the groundnut growing regions of seven other states in India). This is part of the Legumes On-farm Testing and Nursery Unit (LEGOFTEN), an initiative supported by the Government of India and ICRISAT in the late 1980s. The development of GPT in India was initially motivated by the need to enhance groundnut production and yield to meet the rising demand in the country during the 1980 s and to reduce the import of edible oils.

\section{Approaches}

Using the case study of ICRISAT's GPT, a systematic documentation of the process by which farmers - both men and women - as well as the whole community became empowered through the build-up of social capital in village Umra is presented in this paper. It summarizes and synthesizes the findings from three studies carried out by ICRISAT during the last decade, as illustrated below.

A survey conducted during the early 1990s in Maharasthra, India showed that there was fairly widespread adoption of the technology in the late 80 's, but the adoption was partial and step-wise. A parallel evaluation of the technology employing a gender perspective ${ }^{3}$ revealed changes in the intra-household distribution of benefits, and changes in access to and

\footnotetext{
${ }^{3}$ With the aim of providing appropriate feedback to scientists in designing technologies which can incorporate a 'gender perspective' that can enhance technology adoption and its impact on the household scenario, ICRISAT began considering gender differences in preferences for alternative variety traits and in farm investment priorities, as well as assessing the welfare impacts of groundnut technologies and examining gender-related indicators for targeting nutrition interventions.
} 
control over different post-harvest products (Kolli and Bantilan 1997). After a decade of technology introduction, significant impacts on a number of indicators to diverse social groups became evident in a survey carried out in 1999. It was observed that a stream of benefits flowed to adopters due to changes resulting from the use of the GPT innovation. These include direct benefits (i.e., benefits measured in terms of increases in on farm groundnut yields and income), and indirect benefits (i.e., changes in community welfare and farming system viability). Direct benefits include an increase in income and yields as a result of adoption of the GPT and greater stability of the cropping system. Indirectly, adoption has improved food availability and nutrition, and led to crop diversification and ownership of assets. Assets acquired for GPT are being used for other crops, and have enabled cultivation in other seasons. Initial benefits in the form of higher profits and income were reinvested in order to obtain long term benefits and to stabilize the farming system.. Finally, stability of the farming system has expanded choices, such as increasing the freedom of farmers to take decisions regarding the cropping pattern (e.g. cash vs. subsistence crops or market vs. subsistence orientation, investing in production vs. investing in education, housing, or household assets)

In carrying out an informal survey to assess impacts, in attempting to find causal relations between technology traits and the perceived impacts, and in the process of unearthing the reasons for lack of impact during an earlier study, the role of social capital and collective action in successful adoption and impact in the village was identified. 
Three phases depict the results of ICRISAT's investments from the perspective of the various actors - male farmers, socially marginalized groups, agricultural workers and women as shown in figure 1. Correspondingly, evolving approaches in assessing the economic, social and environmental impacts over time are presented in three phases shown in figure 1.

Figure 1. Tracking poverty impacts at ICRISAT, 1992-2003

Phase 3: Late 1990s-Early 2000: Late 1990s Exploratory surveys- Flow of benefits to diverse groups; role of social capital

Case study- Gender and social capital mediated technology uptake

Phase 2: Early 1990s: Gender Analysis of GPT- Differential perceptions and gender-related impact indicators

Phase 1: Early 1990s: Impact Assessment of GPT - Economic impacts and environmental impacts

A combination of quantitative and qualitative methods of data collection were used during these three phases of learning, and through a monitoring and evaluation exercise, the process of empowerment was tracked down in a similar manner as presented in Figure 2. 
Figure 2. Framework for monitoring and evaluation of GPT in village Umra, India 1992-2003.

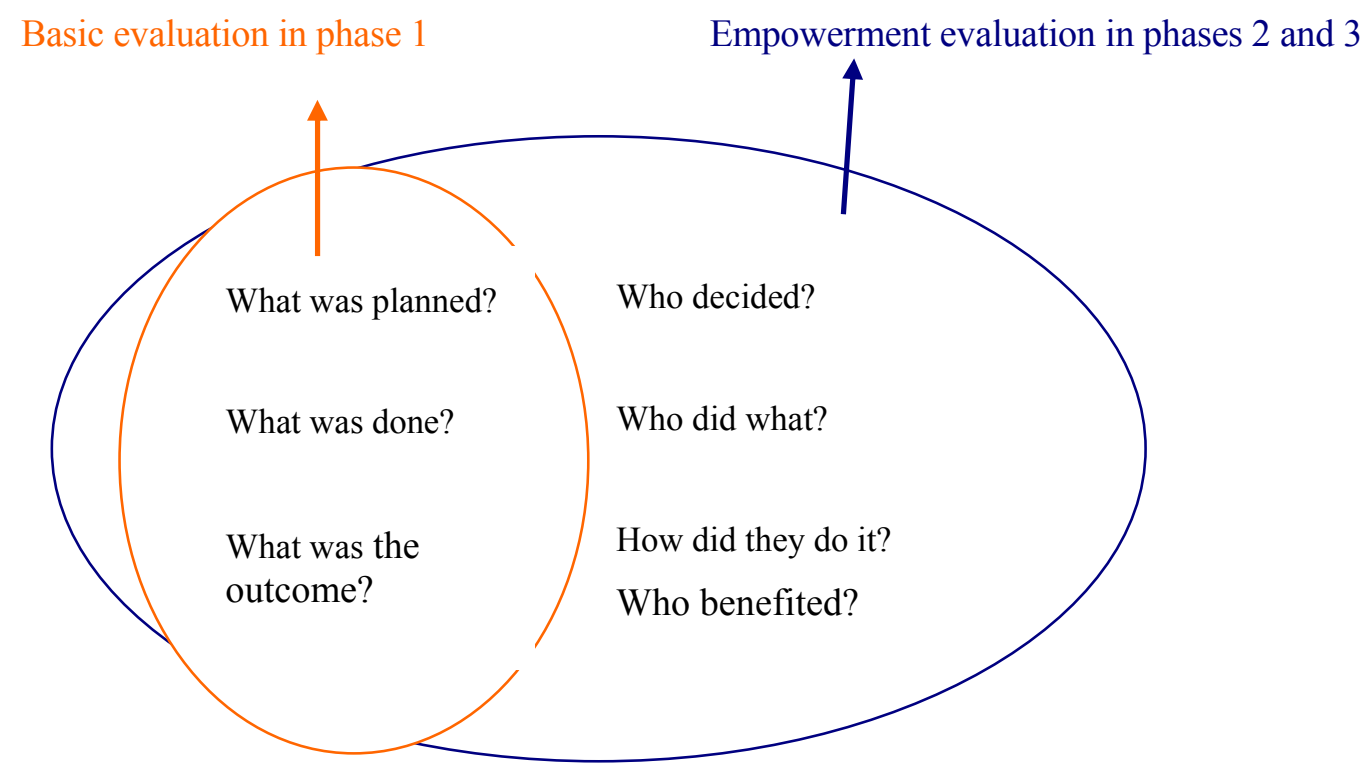

Source: Adapted from Bartlett, 2004

ICRISAT's approach of integrating analyses of social capital and empowerment emerged from the earlier studies as an embedded hypothesis. The observation in earlier case studies was that people were developing various kinds of networks and norms of sharing and reciprocity in adopting the technology. Some of the networks were based on kinship networks, but some of them actually evolved for a specific purpose (Parthasarathy and Chopde 2000). This finding has led us to look more closely into how the networks are built, who is benefiting and how are they benefiting, and the role of different members in the group. Thus, in this case, the technology uptake process was followed up in phase three by examining the interplay of factors, including gender dimensions, in social capital build-up. 


\section{FINDINGS}

\section{Learning Phase 1 - Economic impact assessment of GPT: Quantifying returns to investment}

This phase was concerned with looking at the technology that was planned, designed and developed for cultivation of groundnuts and its outcome (adoption and non-adoption), as well as the returns to research investment.

\section{Method}

This assessment of GPT in the early 1990's is part of a series of case studies on adoption and impact that were carried out by ICRISAT in Asia and Africa. The case studies helped in identifying constraints to adoption and characteristics preferred by farmers that were also important contributions to formulation of ICRISAT's overall research strategy. In this process, the tangible benefits from ICRISAT crop improvement and natural resource management research were identified. This included quantifying the returns to investment, and looking at the economic and environmental impacts of GPT among other technologies developed. The GPT impact study was also concerned with adoption tracking of the different crop and resource management options and estimation of research cost and evaluation of research benefits. Focus group meetings (FGM) were conducted between late 1994 and mid 1995 to track the adoption of different components of GPT. Relevant information was also collected from selected farmers - both men and women - using structured questionnaire(s).

GPT was targeted at eight states of the Indian semi-arid tropics: Andhra Pradesh, Gujarat, Karnataka, Madhya Pradesh, Maharashtra, Orissa, Tamil Nadu and Uttar Pradesh. It 
was only in Maharashtra that government and non-government agencies followed up the dissemination of the technology. Since the objective in this phase was to assess adoption and evaluate the impact of the package, Maharashtra state was selected to confirm the adoption of the technology. The study sample was 355 farm households from 33 villages from four districts of Maharashtra, namely Amravati, Nanded, Parbhani, and Yavatmal.

\section{Findings}

Adoption of the technology had positive impacts in terms of higher gains in yield and income, better farm prices, and saving of important inputs. The technology generated employment (particularly for the female labor force) and improved labor productivity.

Joshi and Bantilan (1998) observed a partial and step-wise adoption of different components of the technology that range between 31 and 84 percent. Farmers also modified the technology options according to their needs, convenience, and resource endowments. In comparison to the prevailing technology, the groundnut production technology gives 38 percent higher yields, generates 71 percent more income and reduces unit cost by 16 percent. The technology also contributes to improving the natural resource base and eases certain women-specific agricultural operations such as weeding. The total net present value of benefits from collaborative research and technology transfer is more than US\$ 3 million, representing an internal rate of return of 25 percent.

Learning

The Broad Bed and Furrow (BBF) method of cultivation became popular amongst farmers. It was noted that the adoption of different components of the technology was associated largely with the BBF method, with adoption of all components being significantly higher among those who had adopted this method. The probability of adopting the BBF was 
high when farmers had access to a technology-generating and technology-transfer system. Availability of appropriate implements, capital, and irrigation also determined the adoption of the BBF option. The other components, especially the sprinkler method of irrigation, required better market access for adoption. Also, a need for well-designed cost-effective suitable implements that will facilitate easy maintenance of the BBFs was identified. The technology generated modest economic surplus for consumers and producers, with the latter being the primary beneficiaries. Identification of constraints to adoption of different components of the GPT was suggested to propose an appropriate strategy for the wide-scale adoption of the technology. Labor productivity and gender implications were also noted to be important impact indicators that require further attention. Lastly, the study focused on quantitative indicators alone and qualitative benefits from the technology were not looked into.

\section{Learning Phase 2 - Gender analysis of GPT: Identification of gender- related impact indicators}

\section{Method}

An ex-post gender analysis to examine the differential effects of groundnut crop production technology on men and women farmers was undertaken in the early to mid 1990's. A gender analysis of the technology package was undertaken to identify who does what activity; who has access to and control over resources used for crop production and who has access to and control over the benefits from groundnut crop. The analysis focused on labor and resource allocation and the distribution of the benefits of this technology across farm and labor households and among different men and women members in these households who adopted this technology. The study team was inter-disciplinary in composition and employed 
data collection tools such as PRA, and RRA along with individual interviews, in order to assess male and female farmers' perceptions regarding the new technology and to evaluate their needs in view of changes stemming from the technology introduction. Gender analysis examined considerations beyond gender roles and evaluated differences in the priorities men and women attach to alternative grain and plant traits.

The analysis of gender-differentiated impacts followed the dynamics that emerge within and among farm-households after technology intervention. It was hypothesized that introduction of new technology affects different members of the households in varying ways and that these consequences are empirically verifiable. Evidence based on two village level studies were examined to clarify, as well as to draw implications for appropriate technology design, the differences in the roles, access and benefits of men and women. Two surveys specifically targeted for gender analysis were used in this study. They were designed to compare 'with' and 'without' technology situations and to analyze changes in intra-household relationships as a result of adoption of improved technology options. Two villages, Umra and Karanji, within Kinwat taluk of Nanded district in Maharashtra state were selected for qualitative and quantitative surveys conducted during the period 1992-94. Umra represented the 'with' technology situation, where the groundnut production technology (GPT) package was taken up successfully by groundnut producing farm-households. Karanji, in contrast, represented the 'without' technology situation, where the GPT technology diffusion has not taken place. These two villages were carefully selected after considerations of their homogenous socio-economic characteristics, agro-climatic environments and cropping patterns (Table 1). 
Table 1--Village profiles, Umra and Karanji villages, Maharashtra, 1991/92

\begin{tabular}{|c|c|c|c|c|}
\hline $\begin{array}{l}\mathrm{Sl} \\
\text { No } \\
\end{array}$ & \multicolumn{2}{|c|}{ Characteristics } & \multirow{2}{*}{$\begin{array}{l}\begin{array}{l}\text { Umra } \\
\text { (Experimental village) }\end{array} \\
54\end{array}$} & \multirow{2}{*}{$\begin{array}{l}\begin{array}{l}\text { Karanji } \\
\text { (Control village) }\end{array} \\
51\end{array}$} \\
\hline & Percentage of total number of & Farm households & & \\
\hline & & Agricultural labor households & 39 & 33 \\
\hline & & Others & 7 & 16 \\
\hline & & Total & 100 & 100 \\
\hline & $\begin{array}{l}\text { Percentage of farm households } \\
\text { growing groundnut in summer }\end{array}$ & & 37 & 20 \\
\hline & Soil type & & $\begin{array}{l}\text { Black to deep black } \\
\text { soils }\end{array}$ & $\begin{array}{l}\text { Medium to deep } \\
\text { black soils }\end{array}$ \\
\hline & Annual rainfall (at taluka level) & & $817 \mathrm{~mm}$ & $817 \mathrm{~mm}$ \\
\hline & Sources of irrigation & & Well & Well \\
\hline & Major crops grown & & $\begin{array}{l}\text { Cotton } \\
\text { Sorghum (HYV) } \\
\text { Groundnut } \\
\text { Pigeonpea } \\
\text { Wheat }\end{array}$ & $\begin{array}{l}\text { Cotton } \\
\text { Sorghum (HYV) } \\
\text { Groundnut } \\
\text { Pigeonpea } \\
\text { Paddy } \\
\text { Wheat }\end{array}$ \\
\hline & Major sources of income & & $\begin{array}{l}\text { Crops } \\
\text { Wage labor } \\
\text { Livestock } \\
\text { Trade \& } \\
\text { Others }\end{array}$ & $\begin{array}{l}\text { Crops } \\
\text { Wage labor } \\
\text { Trade } \\
\text { Livestock \& } \\
\text { Others }\end{array}$ \\
\hline
\end{tabular}

Source: Kolli and Bantilan 1997.

A representative sample of 26 farm-households was randomly chosen from each village. These two samples were drawn from farm-households who own or hire land for cultivation. Household census surveys were first conducted for both villages in order to obtain a list of the households growing groundnut and a list of those who have adopted the improved technology. A similar sampling frame was developed for Karanji (without technology) where households cultivating groundnut crop since 1987 were enumerated.

\section{Findings}

Kolli and Bantilan (1997) identified the following indicators with strong implications for gender due to the introduction of the GPT. These indicators are - a) labor-activity pattern 
and time allocation, b) decision-making behavior of men and women with regard to resource use and utilization of crop products; and c) user perspective - differential perceptions of men and women with implications for technology development.

A gender analysis of the technology revealed that adoption of new technologies enhanced task specialization where activities were performed exclusively by a particular gender in order to optimize available household labor resources. The new technology also required more labor input by both men and women, about 26 hours in male labor requirements and 16 hours in female labor requirements for the summer crop. The adoption of the GPT package also significantly increased the use of female hired labor as shown in Table 2. Gender roles are segregated into types of work (men do heavier jobs and women do lighter jobs) and into market and domestic activities where men gain greater control over marketrelated activities and women over the domestic realm.

The qualitative implications of higher yields were also examined. Higher yields from GPT allowed households to diversify use of the products of the groundnut crop. In this process, women gained control over the products retained for household use. Men were mostly concerned about financial viability of the technology while women were found to perceive the advantage of the new technology options in terms of workability and implications for drudgery and occupational hazards.

An evaluation of the grain and plant traits indicated that women in the survey villages prefer varieties which are easier to uproot and shell and that offer high grain yields and good taste. Men seemed to prefer varieties with better fodder yield and larger seeds attracting better market prices. 
Table 2--Operation-wise use of male \& female labor time, summer groundnut crop activities, Maharashtra 1991/92, (Hrs per acre)

\begin{tabular}{|c|c|c|c|c|c|c|c|c|}
\hline \multirow{3}{*}{ Activity } & \multirow{2}{*}{\multicolumn{5}{|c|}{ Family Labor }} & \multicolumn{3}{|c|}{ Hired Labor } \\
\hline & & & & & \multirow[b]{2}{*}{$\mathbf{U}$} & \multirow{2}{*}{$\frac{\text { Male }}{\mathrm{K}}$} & \multicolumn{2}{|c|}{ Female } \\
\hline & $\mathbf{U}$ & $\mathbf{K}$ & $\mathbf{U}$ & $\mathrm{K}$ & & & U & $\mathrm{K}$ \\
\hline $\begin{array}{l}\text { 1. Land preparation } \\
\text { (Field cleaning, clod crushing, ploughing \& harrowing) }\end{array}$ & 18.38 & 25.16 & 9.08 & 13.57 & 21.98 & 23.25 & 25.95 & 25.98 \\
\hline 2. $\frac{\text { Soil preparation }}{\text { (Preparation of broadbed \& furrow / Ridges \& furrow) }}$ & 1.88 & 6.43 & 0.07 & 1.16 & 2.58 & 11.35 & 0.00 & 0.00 \\
\hline $\begin{array}{l}\text { 3. Transport \& application of manure / fertilizer - basal } \\
\text { and top dressing }\end{array}$ & 11.03 & 6.50 & 6.27 & 3.93 & 12.94 & 9.91 & 18.90 & 4.10 \\
\hline $\begin{array}{l}\text { 4. Seed treatment \& sowing operations } \\
\text { (Hand dibbling / seed drill) }\end{array}$ & 7.27 & 9.57 & 6.78 & 10.05 & 3.93 & 4.55 & 59.19 & 57.68 \\
\hline 5. Irrigation (Sprinkler / Traditional method) & 14.64 & 43.56 & 2.69 & 5.78 & 13.88 & 32.96 & 1.06 & 0.00 \\
\hline 6. Intercultivation \& hand weeding & 6.48 & 10.19 & 24.37 & 19.21 & 6.02 & 5.74 & 116.78 & 126.94 \\
\hline 7. Plant protection (Application of gypsum, micronutrients, spraying of pesticides \& crop & 117.73 & 78.26 & 20.92 & 10.36 & 30.28 & 7.01 & 6.48 & 0.41 \\
\hline 8. Harvesting groundnut (Pulling/uprooting plants, stripping pods from plant $\&$ drying/cleaning & 23.98 & 28.79 & 28.64 & 35.08 & 14.65 & 24.07 & 151.98 & 105.44 \\
\hline & 20.09 & 19.08 & 1.50 & 0.21 & 13.59 & 9.26 & 0.12 & 0.00 \\
\hline 9. Transport \& marketing of main product, purchasing inputs, transport of fodder & 6.14 & 10.50 & 4.67 & 4.92 & 14.05 & 7.25 & 1.61 & 0.82 \\
\hline 10. Collection, stacking \& storage of groundnut fodder & 4.73 & 4.48 & 22.05 & 5.26 & 0.88 & 0.00 & 14.62 & 6.38 \\
\hline 11. Storage \& processing of groundnut (includes shelling pods and sorting kernels for seed) & 79.10 & 42.53 & 16.34 & 16.89 & 0.00 & 0.00 & 0.00 & 0.00 \\
\hline 12. Supervision & 311.43 & 285.05 & 143.38 & 126.42 & 134.77 & 135.35 & 396.69 & 327.74 \\
\hline
\end{tabular}

TOTAL 


\section{Learning}

The lessons learned from the above findings highlight the need to consider the distinct needs of both men and women in prioritizing varietal traits. Similarly these differences may also affect varietal adoption patterns and seed marketing strategies. Important qualitative data enhances understanding of how men and women assess the benefits of adoption, as well as how decision making power is shared among household members. These are useful indicators of real gains enjoyed by different household members. Integration of genderdifferentiated quantitative data with qualitative information provides a holistic basis for capturing the effects of technology intervention in terms of balance of efficiency and equity consequences. It can be concluded that a research and development agenda which incorporates analysis of gender disaggregated farmer perspectives is likely to lead to a more appropriate and acceptable technology, which will gain further and wider adoption.

Research on the adoption of the groundnut crop management technologies suggests the complexity of efforts to measure impacts of technological change on gender and family welfare. Literature suggests that technologies targeted toward the needs of women will have a greater likelihood of improving family food security broadly and child nutrition in particular. But we also need to account for a wide range of impact interactions. For example, the adoption of a package of groundnut technologies (including new land preparation and planting methods, seed treatment, fertilizer use and irrigation) recommended for farmers in Maharashtra has led to aggregate increases in female labor demands, but most of the gain is in hiring of female wage labor. Survey evidence suggests aggregate production and income gains which seem to improve the welfare of both men and women. While some of the additional 
grain production is used for household consumption, a major share is sold with the cash income controlled by men. The ultimate distribution of benefits is difficult to measure. In tracking benefit flows from technology adoption, it is thus necessary to establish relationships between different factors and interventions, which are likely to affect the flow of benefits as well as the groups who may benefit.

\section{Learning phase 3 - Social impact assessments: build-up of social capital}

\section{Method}

Enhancement of the impact measurement beyond productivity gains and internal rates of return from GPT, benefits to women, was undertaken during this phase to look into the social dimensions of poverty (e.g. the build-up of social capital). Initial exploratory surveys and the case study on gender and social capital mediated technology uptake in this phase not only documented clear impact in terms of increased yield and income, but also gave insights on understanding the processes whereby technology adoption leads to welfare changes. An assessment of the magnitude to which these impacts have actually translated into welfare changes was also undertaken in this phase. Using gender and social impact assessment tools adapted from the World Bank (Narayan and Srinivasan 1994), this study takes into account the complex social relationships as well as the changing perceptions of status within the family and community. Two of the tools used are a participatory exercise in gender analysis to assess the degree of women's participation and self-confidence and a participatory exercise in gender analysis to determine what poverty means to a particular community and thereby enable the community to decide which of its members should be targeted to receive most 
assistance. These tools were used to learn how the women members of self-help groups (SHGs) are targeted to receive assistance.

The study was carried out in two villages - Umra (experimental village) and Ashta (control village) in the state of Maharashtra, India where the technology had been introduced at almost the same time in 1987. The profiles of the two villages are presented in table 3. A household census was undertaken in the both the study villages, for sample selection. Stratified random sampling was then adopted to select the sample households for the questionnaire surveys as well as for focus group meetings. The sample consisted of 161 households from Umra (experimental village) and 284 households from Ashta (control village), covering about 15 percent of the households from each village. 
Table 3--Classification of households by land holding size, Umra and Ashta villages, Maharashtra, 2002-03

\begin{tabular}{|c|c|c|c|c|}
\hline SI. & \multicolumn{2}{|c|}{ Characteristics } & Umra & Ashta \\
\hline 1. & $\begin{array}{l}\text { No. of households \& percentage of } \\
\text { total number of households }\end{array}$ & Farm households & $114(67 \%)$ & $170(60 \%)$ \\
\hline & & Agricultural labor households & $48(28 \%)$ & $100(35 \%)$ \\
\hline & & Others & $8(5 \%)$ & $14(5 \%)$ \\
\hline & & Total no. of households & 170 & 284 \\
\hline \multirow[t]{4}{*}{2.} & $\begin{array}{l}\text { Percentage of farm households by land } \\
\text { holding size }\end{array}$ & Small farmers & $40(35 \%)$ & $69(41 \%)$ \\
\hline & & Medium farmers & $35(31 \%)$ & $61(36 \%)$ \\
\hline & & Large farmers & $39(34 \%)$ & $40(23 \%)$ \\
\hline & & Total & 114 & 170 \\
\hline \multirow[t]{4}{*}{3.} & $\begin{array}{l}\text { Percentage of farm households } \\
\text { growing groundnut }\end{array}$ & Small farmers & $12(18 \%)$ & $0(0 \%)$ \\
\hline & & Medium farmers & $23(34 \%)$ & $14(47 \%)$ \\
\hline & & Large farmers & $32(48 \%)$ & $16(53 \%)$ \\
\hline & & Total & $67(59 \%)$ & $30(18 \%)$ \\
\hline \multirow[t]{4}{*}{4.} & $\begin{array}{l}\text { Percentage of farm households } \\
\text { growing groundnut in summer }\end{array}$ & Small farmers & $8(66 \%)$ & 0 \\
\hline & & Medium Farmers & $12(52 \%)$ & $14(100 \%)$ \\
\hline & & Large farmers & $24(75 \%)$ & $16(100 \%)$ \\
\hline & & Total & $44(66 \%)$ & $30(100 \%)$ \\
\hline \multirow[t]{4}{*}{$* * 5$} & $\begin{array}{l}\text { Percentage of groundnut growing } \\
\text { households adopting GPT }\end{array}$ & Small farmers & $12(100 \%)$ & 0 \\
\hline & & Medium farmers & $23(100 \%)$ & $9(64 \%)$ \\
\hline & & Large farmers & $32(100 \%)$ & $14(88 \%)$ \\
\hline & & Total & 67 & $23(77 \%)$ \\
\hline \multirow[t]{4}{*}{6.} & $\begin{array}{l}\text { Percentage of groundnut growing } \\
\text { households adopting GPT selected as } \\
\text { sample }\end{array}$ & Small farmers & $5(42 \%)$ & 0 \\
\hline & & Medium farmers & $8(35 \%)$ & $5(56 \%)$ \\
\hline & & Large farmers & $11(34 \%)$ & $6(43 \%)$ \\
\hline & & Total & $24(36 \%)$ & $11(48 \%)$ \\
\hline 8 & $\begin{array}{l}\text { Percentage of Landless farmers } \\
\text { selected as sample }\end{array}$ & & $14(29 \%)$ & $16(16 \%)$ \\
\hline
\end{tabular}

Figures in parenthesis indicate the percentage of households.

Large farm size: 2.5 ha and above; Medium farm size: 1.25 to 2.49 ha; Small farm size 0.04 to 1.24 ha 


\section{Findings}

An interesting feature that was observed in the experimental village of Umra was the build up of social capital as a result of adoption of the GPT. The widespread adoption of the GPT package was attributed to the strong cooperation that evolved among the landholding farmers, the landless laborers, tribal groups and women. Focus group meetings and social analysis revealed that the technology uptake process increased in Umra with the build up of social capital, whereby the men and women from all class and caste groups come together [for example, in the formation of the farmers group Krishi Vikas Mandal (KVM) and self-help groups (SHGs) among small and medium land holding, landless and tribal women] and overcame problems of institutional access to information, credit and other resources for crop production like tools and implements., as well as seed supply and provision related problems arising out of government and private sector inefficiencies. It also enabled large-scale adoption and resulted in positive impact in terms of higher yields and incomes for farm and labor households, as well as other less tangible and indirect gains. Ultimately, sharp class and caste distinctions were shattered.

GPT adopters in Umra revealed that collective action and social capital were instrumental in high adoption levels of the technology in the village. The technology was first adopted by a few farmers from the large land holding class, with little or no education, after it was introduced to them. Initially, adoption of the technology was very poor and there was only partial adoption of the technology package. Since the farmers did not have the knowledge to use different components of the technology in the right way, it resulted in more harm than good. For example, farmers did not know how to assemble the sprinkler sets and 
use water optimally, and thus the small group of adopters was on the verge of discarding the technology. It was at that time that a farmers' mela (fair) was organized at a nearby town. The group of initial adopters together with some other farmers, mostly from the medium land holding class, went as a group to this fair, participated in the discussions, sought clarifications and accepted the challenge to use the technology. The challenge was taken up by a medium land holding, educated farmer. The KVM farmers group was formed during this time. Several other farmers joined in this process, and they became very successful in using and benefiting from the technology. A striking feature is that it was only when the farmers came together as a group did they realize the potential of the technology package and its benefits. Their success motivated other farmers in the village to adopt the technology.

As was observed by Parthasarathy and Chopde (2000), farm households had short, medium and long term planning horizons in deciding how to use the benefits of the new technology for improving their socio-economic conditions as well as for improving their livelihoods and developing strategies to sustain the flow of benefits from their farming activities. Over a long period poverty had forced many households to take loans from various sources which they could not repay, as well as to sell or pledge their valuables, especially gold and silver ornaments. In the initial few years after the technology was adopted, farm households jointly paid off their debts both to redeem their valuables - which are important sources of security in times of distress - as well to close the loans so that new lines of credit may be opened for consumption and production purposes. In a remarkable act of unity and based on rational evaluation of future possibilities, households actually pooled their resources to clear past debts. 
Since the technology was fairly complex and needed initial investments, opening of credit lines was of importance despite the government subsidies for some of the capital investments. Significantly, the mobilization of social capital for this purpose and the stability of yields in the initial years improved the credit worthiness of the households. Formal institutions such as banks as well as retails suppliers of inputs such as seeds and fertilizers were more willing to give credit compared to earlier times.

Multiplier effects were observed through time, showing improvement in various dimensions: farm production, cropping pattern, consumption, and ownership of assets, as detailed below:

Farm production: From the focus group meetings and key informant interviews with men and women farmers of Umra it was clear that collective action was extensively used for procuring inputs for crop production (especially gypsum and culture for seed treatment), access to resources (implements, BBF, seed drill), knowledge sharing and dissemination, and empowerment of both men and women farmers. Credit access, provision of health and sanitation facilities, investment in children's education and almost every sphere of life improved in dynamic proportions. ${ }^{4}$

Cropping pattern: The cropping pattern for groundnut cultivation increased from one to three cropping seasons per year as shown in table 4. As a result of year round agricultural activities in Umra, the people, especially women, have year round employment, which has led to an increase in income. Focus group meetings and informal discussions with men and women farmers revealed that out migration of labor was replaced with in migration. People

\footnotetext{
${ }^{4}$ See Video Documentary entitled, "Together we sow, Together We reap" produced by ICRISAT 2004 , for a visual presentation of these observations.
} 
did not have to go out of the village in search of employment. Cultivation of high-value crops like soybean, and chickpea has also increased.

Table 4--Changes in cropping pattern across seasons

\begin{tabular}{|c|c|c|c|c|c|c|}
\hline & $\begin{array}{l}\text { Umra - } \\
1992-93 \\
\text { (area in ha) }\end{array}$ & & $\begin{array}{l}\text { Umra - 2002-03 } \\
\text { (area in ha) }\end{array}$ & & $\begin{array}{l}\text { Ashta - 2002-03 } \\
\text { (area in ha) }\end{array}$ & \\
\hline \multirow{5}{*}{ Kharif (Rainy) } & Cotton & 59 & Cotton & 44 & Cotton & 62 \\
\hline & Sorghum & 22 & Soybean & 28 & Sorghum & 32 \\
\hline & Pigeonpea & 6 & Sorghum & 13 & Soybean & 10 \\
\hline & Others & 10 & Groundnut & 9 & Groundnut & 3 \\
\hline & & & Others & 3 & Others & 5 \\
\hline \multirow{4}{*}{ Rabi (Post-rainy) } & Chickpea & 14 & Chickpea & 23 & Chickpea & 13 \\
\hline & Wheat & 8 & Groundnut & 15 & Groundnut & 4 \\
\hline & Groundnut & 2 & Wheat & 2 & Wheat & 5 \\
\hline & & & Others & 2 & Others & 2 \\
\hline Summer & Groundnut & 23 & Groundnut & 19 & Groundnut & 6 \\
\hline
\end{tabular}

Consumption pattern: An analysis of the consumption pattern of households reveals that fluctuation in consumption of small land holding farmers and landless labor households across the seasons is less in Umra compared to the control village Ashta (Figure 3). This is so because of the maintenance of the food security status of the household through self-help groups (SHGs) and kinship networks by women. Social capital supports this role of women through sharing of knowledge related to food and nutrition as well as sharing of essential consumption items during times of crises. While women from the landless and small landholding households contribute to family food security through direct wage earning and domestic activities, women from the medium and large landholding households do so through increased income from the year round farm activities. 
The food platter of the large and medium land holding farmers improved; they had more variety and the quality of life also improved. The landless labor and small land holding farmers have more food as they have enough money to buy sufficient food and they are able to pay off some of their debts because of GPT. Children of labor families are also attending school. It was noted that men and women of the control village of Ashta lacked year round employment, and hence food insecurity prevailed, especially among the small land holding farmers and landless labor. 
Figure 3-Fluctuation in consumption across seasons

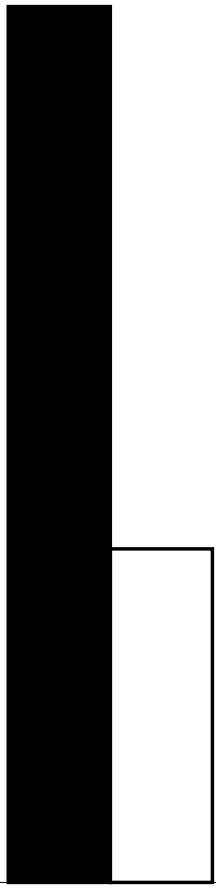

Lean

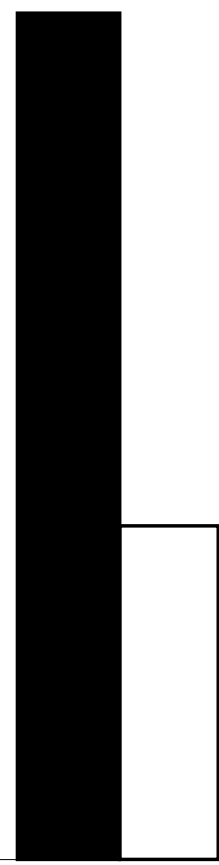

Medium

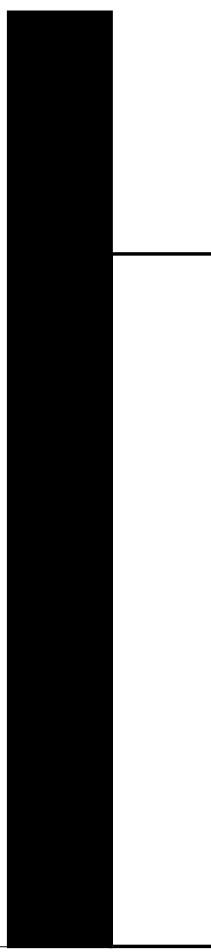

Peak

Seasons

Umra

Ashta

Asset ownership: An upward mobility in terms of land ownership was seen in Umra when compared with benchmark data of 1992-93 (Figure 4). It was observed that while there is an increase in the number of land owning farm households, the total number of households remained the same. Focus group meetings corroborated this finding, indicating that an increase in employment opportunities due to GPT adoption has led to many of the labor households acquiring land. 
Because of the increase in income, through crop cultivation or wage earnings, housing and amenities in Umra saw an improvement. The large and medium land holders renovated their houses, purchased television sets, refrigerators, air coolers, gas stoves, grinders, and dug bore wells at home for domestic consumption, apart from sending their children for higher education. The small land holders and the landless laborers also improved their housing, purchased television sets, sent their children to schools in a nearby town, and invested in vocational training for their children (e.g. tailoring, and computer training).

Figure 4 - Changes in class levels of households

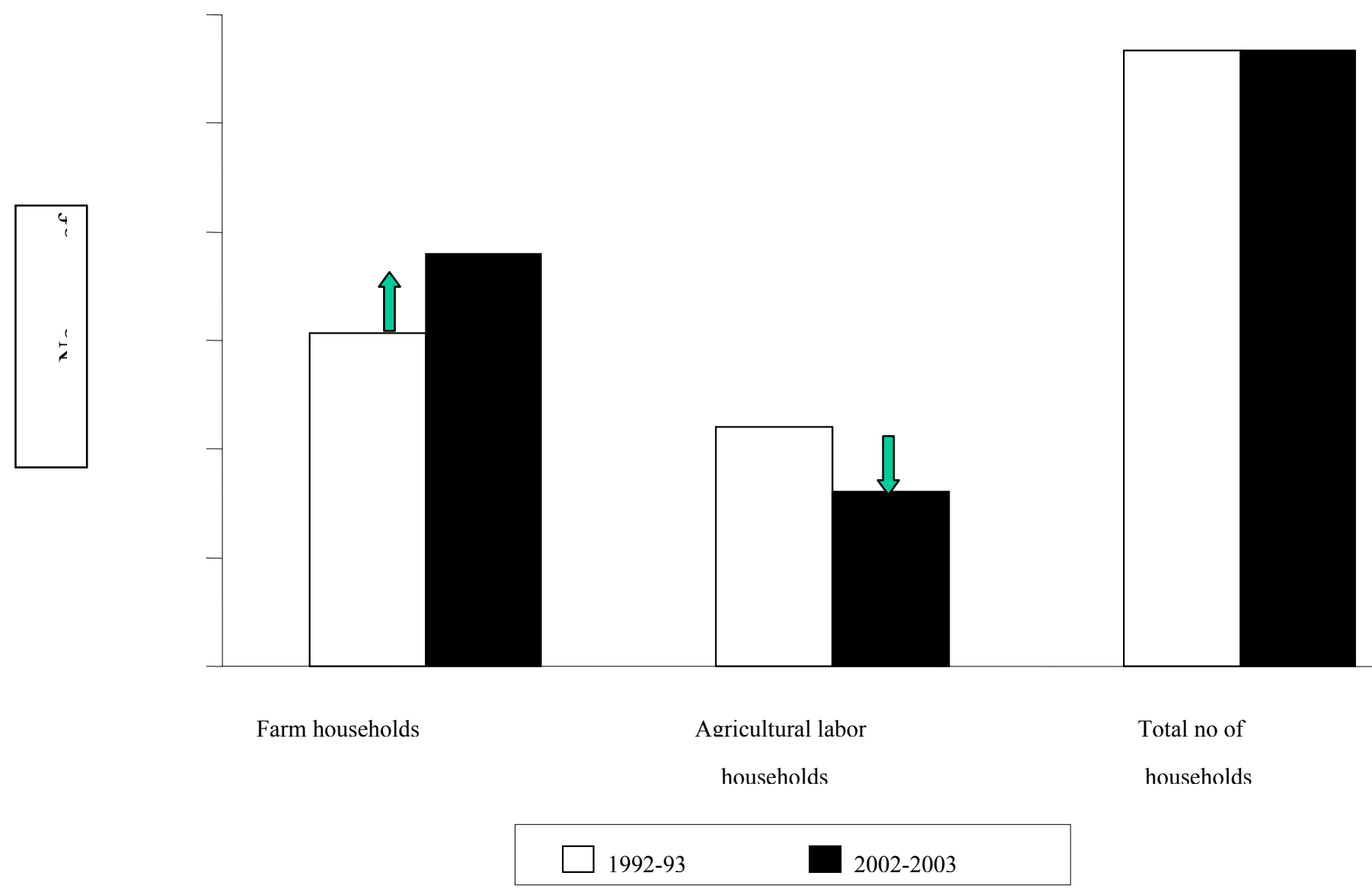

A synthesis of lessons learned in phase 3 is discussed in detail in the following section. 


\section{SYNTHESIS OF LESSONS LEARNED}

\section{Impacts of collective action on gender relations}

Given that the GPT is a complex technology requiring more supervision, care, and labor, its adoption in Umra village motivated group action and the development of better relations with the members of the community, especially among adivasi (tribal) women and men, who were the main source of labor. Better social and political relations were an outcome of technology adoption since everyone stood to gain from it. The men and women farmers in the village also displayed a rare willingness to join hands in repaying their long-term debts and investing in production enhancing assets to improve their creditworthiness. The study revealed specific advantages to women in Umra as a result of social capital mediated technology adoption. The role of women in groundnut production gave it the status of ‘women's crop'. Focus group meetings and key informant interviews revealed that women and the underprivileged class, especially landless tribal women, not only gained higher wages and year round employment, but are now able to bargain for higher wages and are also acquiring political strength and a voice in decision making at the household and community level.

As elaborated by Parthasarathy and Chopde (2000), the importance of collective action and of forging unity with members of other social categories was also felt because of the complexity of the technology in terms of more number of operations to be performed and supervised and hence more dependence on labor. The landowning households therefore consciously attempted to improve relations with the agricultural labor community. In Umra 
the landholding classes mainly belonged to Maratha and other upper caste groups, while predominantly, the adivasis (or lambadas - a tribal group) staying in a separate hamlet in the village, constitute the labor force. Thus links had to be forged at a political level, and the landowning castes consciously attempted to improve relations with the lambada population by acts such as offering the deputy-sarpanch's post to a lambada leader. This is quite significant, as at the time of introduction of the technology in the late 1980s, relations between the two groups were indifferent and hostile. Though much of the agricultural workforce came from among adivasi households, work was available only during a few months during the monsoons, and since there was not much intensive cultivation of the land, demand for labor was low. After the introduction of GPT not only did demand for both male and female labor go up, but work was available almost throughout the year, thus avoiding the need to migrate seasonally in search of employment. Thus on the one hand while the farmers realized the need to maintain good relations with the adivasis in order to avoid labor problems especially during crucial periods, labor households found it convenient to cooperate in terms of long-term security of employment. Many of the agricultural workers were also marginal farmers and so working in their own village made it possible to also work and supervise cultivation of their meager landholdings.

\section{Gender dimensions in build-up of social capital}

Several studies have found that men and women's personal networks differ in composition, although they are similar in size. Men's networks tend to be more formal since men are more often involved in formal employment. Moore (1990) highlights that men's networks include more fellow workers and fewer kin than women's networks do. This feature 
was observed in Umra with the formation of the farmers group, Krishi Vikas Mandal (KVM), a formal organization created to strengthen the weak social ties between the farmers and the labor class. Women's networks tend to be informal (eg. pooja group, mutual finance group/chit fund group, the mahila mandal) ${ }^{5}$ and include more kin relative to men's networks. Contrary to evidence from the literature, it was found that women who were working on the farm as family labor or as paid labor were more aggressive in coming together as a group and discussing their problems and trying to find some solutions to their problems. This was so because they realized that as a group they can work out solutions and ways to solve their problems and not necessarily depend on the male members of the household. A good example of this was the introduction of vocational training for young girls of the village who had dropped out of school. Through their participation in different groups, women were also involved in decisions on how the household spends the extra income gained either through participation in the different groups or from using the GPT- e.g. whether to invest in the farm, purchase consumption goods, and/or invest in health and education of children.

Among income groups, it was observed that women from the low-income category had the strongest kin and community ties. Group formation in SHGs strengthened women's negotiating position, and a change in their roles in household decision-making was observed. Focus was placed on the diversification of skills through developing horizontal networks in the community. An example seen in Umra was vocational training classes for women, especially tailoring.

\footnotetext{
${ }^{5}$ Pooja groups are informal groups of women organized for festive rituals; Mahila mandals are also informal groups of women organized for collective child care, cooking during village gatherings, closing of a local toddyshop, and organizing cultural events at the village level)
} 
Exploring the gendered power relations in the community, it was observed that social networks benefited women. Initially, women were excluded from male-dominated networks such as the KVM and the gram panchayat meetings of the village. With the formation of selfhelp groups and other informal groups, women's agendas and problems began to be considered as important and they were gradually invited to participate in the meetings of the formal groups. When women belonging to self-help groups started using the loans from their savings in ways that improved the economic status of the household (e.g. by investing in poultry rearing and dairying), the male members realized that mutual interaction between the groups would lead to more benefits. Women also were able to hold key positions in the gram panchayats (village councils) as a result of the realization by male members of the community as well as the enforcement of government reservation for women. Focus group meetings with men revealed that the male members of the village were now confident that women could lead village councils.

In Umra, it was observed that women's access to networks outside the household depended greatly on whether other household members, particularly husbands, supported their outside linkages. The focus group meetings also indicated that women's groups are an important source of social cohesion, which in turn is essential for group formation.

Female headed households in Umra were generally poor and did not own implements like BBF markers and sprinklers. Social networks were used to access resources (such as sprinkler sets, BBF markers) especially among female-headed households, who were earlier marginalized as they did not belong to any network. Female-headed households belonged to one or two groups (KVM and SHGs) and they were given priority in accessing resources, 
especially the farm implements. Women belonging to the female-headed households in particular were trained to assemble the sprinkler sets.

Summing up, it can be said that the ability to mobilize themselves leads to beneficial impacts for women and their empowerment in many ways. These include:

- increased employment opportunities, even during the lean season (summer);

- ability to join the SHGs ( since they were earning more money they did not have to depend on male members for contributions to the $\mathrm{SHG}$ );

- increased decision making regarding participation in SHGs,

- vocational training courses (tailoring);

- increased decision making regarding the education of children,

- increased decision making regarding uses of increased income and dietary habits.

The loan obtained from the contributions of women in the SHG was used in the following order of priority - agriculture, education of children, health care, secondary occupations (poultry farming, livestock), and consumption - household durables, repair of homes, jewelry, and clothes.

\section{Role of social networks in empowering women}

The findings from Umra suggest that women who participate in multiple networks (e.g. mutual finance, vocational training, religious groups,) are likely to be empowered and are inclined to seek greater decision-making roles. Also, characteristics that influence women's participation are family and kinship ties and marital status. For example, the Umra study showed that married women are likely to be in positions of decision making and take an active role in collective decision making meetings because they are better trusted and respected. They are also able to indirectly influence higher-level decisions through their 
husbands and their own kinship networks. Their marriage status gives them a respectable position in the society and allows them access to more networks and thus enables them to generate more social capital.

Social networks were observed to operate along gender lines in that they reflect the gendered nature of power relations between men and women. Women and men of Umra, traditionally separate, belong to different networks, and many programs are set up or operate through "women-only" or "men-only" groups. While such groups ensured participation and improved self-confidence, the "women-only" networks were observed to often lack command and authority compared to men's networks. As the women's groups grew stronger both in terms of membership as well as in their priorities and agendas, some women's groups also have begun to invite participation and support of male members to strengthen their collective position.

Finally, networking requires time, especially when formal group meetings are required. FGM interactions found that this presents a binding constraint especially for women from poor households because of their various livelihood activities and childcare responsibilities.

\section{CONCLUSIONS}

The findings of this study confirm that the build-up of social capital mediated the technology uptake process for GPT. It facilitated procuring inputs for crop production (especially gypsum and culture for seed treatment), access to resources (implements, BBF, 
seed drill), knowledge sharing and dissemination, learning, diversification of farm activities and empowerment of both men and women farmers.

The study observed that social networks, developed either through formal organizations, kinship, neighborhoods, work groups, or informal interactions, are a critical component of social capital. Women's networks facilitated communication, coordination, and the provision of information/knowledge regarding agricultural production, income generation, skill enhancement and food security of family. They created obligations and expectations of reciprocity among their members. The trust, common understanding and knowledge generated more social capital, and hence it can be said that social networks facilitate group action and new institutional arrangements.

Findings and discussions through FGMs spanning different groups in the community men and women, farmers and laborers, tribal and landless laborers - showed that women of Umra drew upon a range of social networks for personal and family livelihood. The Umra case study illustrates that women's groups are vehicles for both individual and collective women's empowerment in decision making. This suggests that networks do generate social capital for individuals, leading to more participation and trust.

Village communities are not homogeneous entities but a combination of complex networks of social relationships. Many factors such as ethnicity, gender, socio-economic status, and power relations determine one's access to information and resources. The findings from this study strengthen the argument that the needs of different populations (whether defined by gender, age, ethnicity, or some other criterion) in areas such as agriculture, employment, health and education are not exactly the same. Hence for policy interventions to be effective, the needs and interests of the target population should be understood and 
incorporated in the policy formulations. The findings also indicate that policy be based on an accurate understanding of the ways in which the socio-cultural characteristics of a particular population influence the relationships that its members have with other fields or domains within the wider society. This study is important since it helps us to better understand how and why people interact collectively with each other, as well as how technology can alter this interaction. An adequate understanding of existing social capital, norms, and power relations in the target regions will avoid furthering the interests of better-off farmers and marginalize the poor.

Including women in decision making in the family and in the community at large leads to the empowerment of the individual, the household, and the community. New knowledge regarding farming practices expands choice. Mobilizing social capital through participation helps in successful adoption and diffusion of technologies. As stated by Parthasarathy and Chopde (2000), participatory approaches and collective action are more likely to result in an enhancement of some forms of human or cultural capital - those related to knowledge regarding innovations, and the use of innovative techniques. Human capital enhancement in the form of knowledge regarding technological options expands choices available to farm households and is a key feature of the empowerment process. These choices relate to cropping patterns, investment strategies, and choices to better manage risk and instability. Expansion of choice has the capacity to reduce constraints on economic and social decision-making. Appealing to the concept of social capital as networks and relationships, further research on the types of social networks that marginalized groups associate with, the networks that powerful groups have access to, and the relationship between the two groups is underway. 
Establishing the network architecture (including networks developed either through formal organizations, kinship groups, neighborhoods networks, work groups, self-help groups, or informal interactions), will allow us to investigate the flow of information and the functioning of power relations in the village. Such investigations should provide better insight into how to improve the impact of particular development programs on rural households, in terms of risk insurance and poverty reduction. The research will also use a social lens to analyze the dynamics of shocks and how social networks are essential in developing coping mechanisms to such shocks. 



\section{REFERENCES}

Asian Productivity Organization. 2002. Role of rural women in food security in Asia and the Pacific. Proceedings of the Seminar on Role of rural women in food security held in Thailand, August 21-25, 2002. Bangkok, Thailand.

Bartlett A. 2004. Entry points for empowerment. Draft report submitted to CARE Bangladesh as part of CARE's Rural Livelihoods Programme (RLP), funded by DFID.

Government of India: Directorate of Economics and Statistics. 1993. Agricultural statistics at a glance. New Delhi, India: Ministry of Agriculture, Directorate of Economics and Statistics.

GT-SAT Futures (Global Theme on SAT Futures and Development Pathways). 2004. Together we sow, together we reap. Video documentary featuring the process of empowerment. Patancheru 502324, India. International Crops Research Institute for the Semi-Arid Tropics.

Joshi, P. K., and M.C.S. Bantilan. 1998. Impact assessment of crop and resource management technology: A case of groundnut production technology. Impact Series no.2. Patancheru 502 324, Andhra Pradesh, India: International Crops Research Institute for the Semi-Arid Tropics

Kolli, R.D, and C. Bantilan. 1997. Gender-related impacts of improved agricultural technologies: identification of indicators from a case study. Gender Technology and Development. 1(3): 371393.

Moore G. 1990. Structural determinants of men's and women's personal networks. American Sociological Review 55: 726-735.

Narayan D and L. Srinivasan. 1994. Participatory development tool kit: Training materials for agencies and communities. Washington D.C.: The World Bank

Padmaja, R., and Bantilan, M. C. S. 1998. Gender differences in groundnut production technology evaluation and choice: ICRISAT experience and relevance for future technology development. Paper presented at the technical consultation on Gender roles in peanut sector for household food security, June 9-11 1998, Bangkok, Thailand. Patancheru, India: ICRISAT.

Parthasarathy, D. and V.K. Chopde. 2000. Building social capital: collective action, adoption of agricultural innovations, and poverty reduction in the Indian semi-arid tropics. Paper presented at the Second global development network conference, December 11-13, 2000, Tokyo, Japan. Patancheru, India: ICRISAT.

Pawar C.S., P.W. Amin, K.C. Jain, J.V.D.K. Kumar Rao, and M.P. Srivastave. 1993. On-farm research on groundnut, prgeonpea, chickpea, and transfer of technology to semi-arid tropical farmers in India, 1987-91. Project completion report submitted to IFAD. Patancheru 502 324, Andhra Pradesh, India: International Crops Research Institute for the Semi-Arid Tropics. (Limited distribution) 
Potdar M.V. and M.M. Anders. 1995. On-farm performance of groundnut genetypes under different land configuration and foliar iron sprays for the correction of iron chlorosis on calcarious soils in India. In Iron nutrition in soils and plants, ed. J. Abadia. The Netherlands: Kluwer Academic Publishers.

Woolcock, M. (2001) 'The place of social capital in understanding social and economic outcomes', Canadian Journal of Policy Research 2 (1): 11-17. 


\section{APPENDIX 1}

\section{History of GPT}

The development of GPT in India evolved with the need to enhance groundnut production and yield to meet the rising demand in the country and to reduce the import of edible oils. In 1986, the Government of India introduced a massive program known as the 'Oilseed Technology Mission', allocating more resources to research and technology transfer activities, and offering remunerative prices to oilseed producers, among other measures. ICRISAT, through its Legume On-Farm Nursery Network (LEGOFTEN), was an active partner with the Ministry of Agriculture and the National Agricultural Research Systems (NARS) in identifying appropriate technology options for increased groundnut production and transferring these during the period 1987-91. LEGOFTEN yielded desirable results. The area under groundnut expanded from 6.84 million ha in 1987/88 to 8.67 million ha in 1991/92, and production increased from 5.88 million tons in 1987/88 to 7.07 million tons in 1991/92 (Government of India 1993). Production of other oilseeds also substantially increased during the late 1980s.

After reviewing all available and relevant research information and carefully identifying production constraints in the major oilseed-producing regions in India, a technology package was integrated at ICRISAT. This package was thoroughly discussed with the NARS and State Departments of Agriculture. Since a particular technological package performed well in one type of environment and poorly in another, a unique technology package was suggested for each location after characterizing soil, climate, nutrients, water, pests, and diseases. Several on-farm trials and demonstrations were conducted in eight Indian 
states, covering Andhra Pradesh, Gujarat, Karnataka, Madhya Pradesh, Maharashtra, Orissa, Tamil Nadu, and Uttar Pradesh. These on-farm trials were launched under LEGOFTEN. During the on-farm trials, the suggested technology options for different locations were regularly monitored, adjusted, and refined to meet local requirements. For example, when the crop showed symptoms of iron deficiency, the application of ferrous sulphate was specifically recommended, and added to the technology package.

The GPT encompasses several components related to soil, nutrient, crop, water, and pest management. The components of the GPT can broadly be divided into:

- land management: preparation of raised-bed and furrows (BBF) for groundnut production;

- nutrient management: efficient application of macro- and micro-nutrients;

- improved varieties: high-yielding variety seeds, seed rate and seed dressing/ treatment;

- insect and pest management: effective control of insects, diseases, and weeds; and

- water management: use of sprinkler sets to improve efficiency of irrigation.

Four components of the GPT package were in use by the farmers before the package was introduced: These included (i) improved varieties, (ii) single super phosphate, (iii) seed dressing, and (iv) seed drying. Other components have been developed through NARS Research and Development, and ICRISAT's Groundnut Improvement Program. ICRISAT's Resource Management and Farming Systems Programs had research data on the land management and configuration system. This area had been extensively researched by ICRISAT scientists since the mid-1970s, thus ICRISAT was interested in the performance of these components. This collaboration with Indian NARS and Ministry of Agriculture in the 
technology transfer program provided an opportunity to confirm the suitability and viability of the concept of farmers' fields.

The raised bed and furrow was viewed as an important component of the GPT. It is prepared by opening a furrow $30 \mathrm{~cm}$ wide and $22.5 \mathrm{~cm}$ deep at $1.5-\mathrm{m}$ intervals to sow four rows of groundnut with a distance of $30 \mathrm{~cm}$ between rows. This specific land preparation system is known as broad-bed and furrow (BBF). Over a period of time, the concept of BBF was modified to suit the requirements of the farmers into narrow-bed and furrow, a bed of 75 $\mathrm{cm}$, and ridge and furrow systems (Figure a). Traditionally, farmers use 1-2 harrowings to sow groundnut on flat land. The advantages of raising the bed and forming furrows were to: (i) reduce soil erosion, (ii) provide surface drainage, (iii) concentrate organic matter and fertilizer application, and (iv) reduce soil compaction around plants. It was initially designed for the micro-watershed of the Vertisol technology to achieve optimal use of land and water resources in rainfed agriculture.

On nutrient management, GPT suggested a balanced and efficient use of macro- and micro-nutrients to control nutrient mining from the soil. These included use of ammonium sulphate, single super sulphate, gypsum, zinc sulphate, and ferrous sulphate. These were recommended after nutrient deficiencies were detected in groundnut-growing regions. The application of macro-nutrients - ammonium sulphate and single super phosphate - had been previously recommended, and was adopted by farmers even before the GPT was packaged. This recommendation was essential because these fertilizers supply nitrogen, phosphorous, sulphur, and calcium, that are essential for the groundnut crop. Gypsum was recommended as a source of calcium to improve pod development. Zinc sulphate and ferrous sulphate were recommended to overcome zinc and iron deficiencies. Potdar and Anders (1995) reported that 
iron chlorosis led to groundnut yield reductions of 32 percent for pod, 18 percent for fodder, and 25 percent for total dry matter production. Therefore, the use of ferrous sulphate was considered important to increase groundnut yields.

Leaf spot, rust, collar rot, and bud necrosis are common diseases of groundnut. The yield losses due to these diseases were estimated to be 20-25 percent. Similarly, 15-20 percent yield losses were caused by insects (Pawar et al. 1993). Collar rot and other seedling diseases are also common in groundnut crops. Very few farmers treat their seed with fungicides. Fungicidal seed treatment was incorporated into GPT package. Similarly, herbicides and pesticides recommended by ICRISAT and NARS, to control weeds and pests before the GPT was developed, were also included in the package.

Water management is another important component of the GPT as irrigation water is scarce in the semi-arid tropics. Irrigation-use efficiency increases with the use of furrows compared to irrigation on flat land. Sprinkler irrigation was included in the GPT to enhance irrigation water-use efficiency.

Varieties developed at ICRISAT were recommended as part of the GPT. Generally, farmers were adopting either local or improved varieties released in the mid-1970s. ICRISAT varieties were high-yielding and less susceptible to pests and diseases. Most of the above components of the GPT package were not new; they were known and independently recommended earlier by various research institutions, including ICRISAT. Ironically, their adoption at farm level was limited, and the most often cited constraints were inadequate information and insufficient resources. 
Figure A: Broad bed and furrow method (BBF) of groundnut cultivation

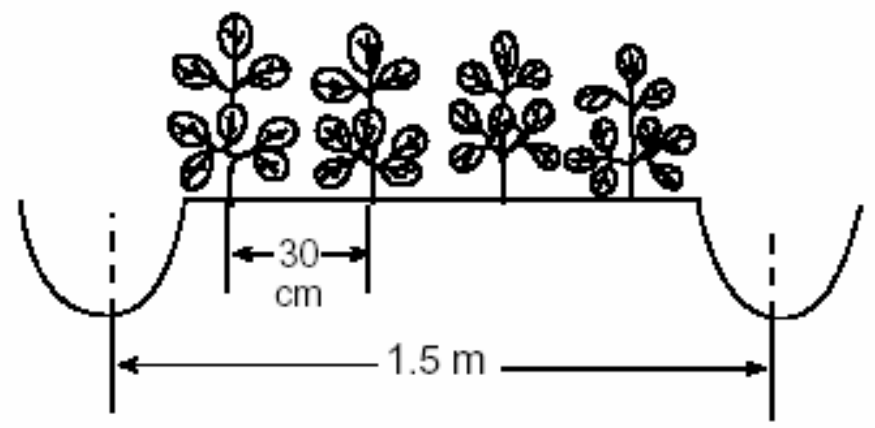

1. Broadbed-and-furrow: ideal for rainy and postrainy seasons, under sprinkler in all soils

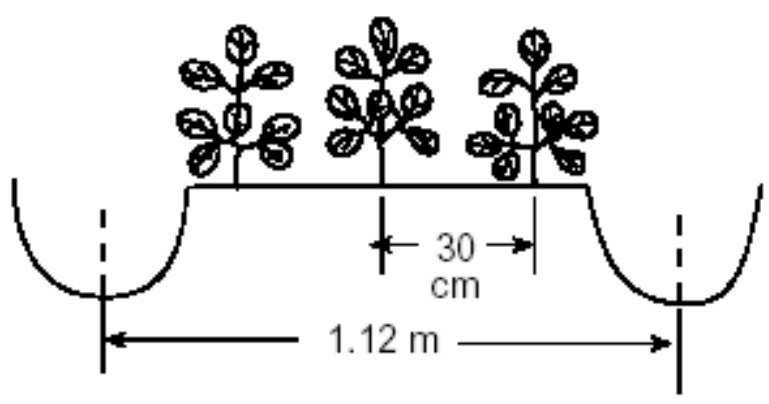

2. Bed and furrow: ideal for rainy and postrainy seasons under furrow irrigation in sandy loam soils
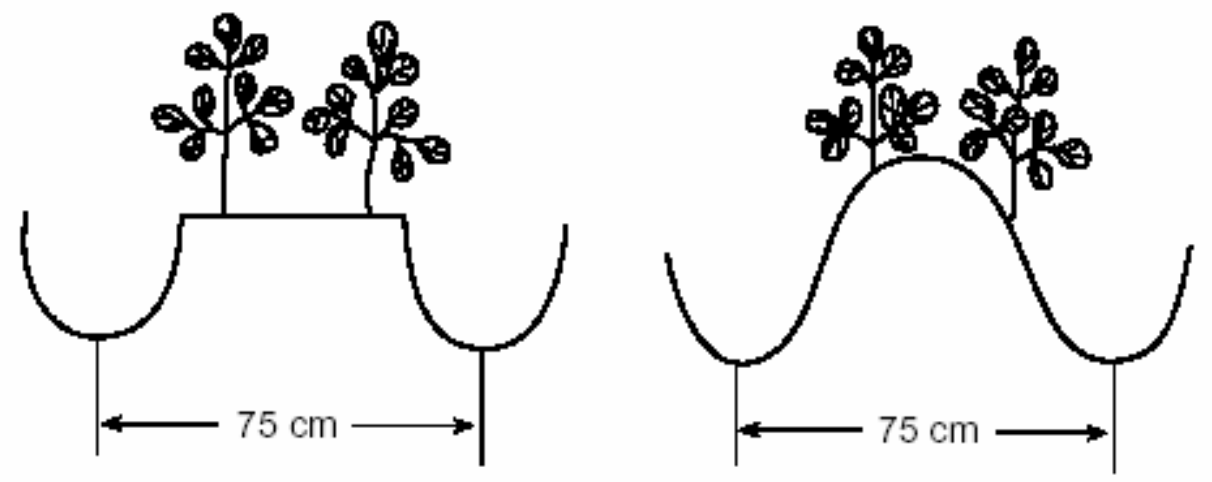

3. Narrow bed or ridge and furrow: ideal for postrainy seasons under furrow irrigation in black and lateritic red soils 



\section{List of CAPRi Working Papers}

01 Property Rights, Collective Action and Technologies for Natural Resource Management: A Conceptual Framework, by Anna Knox, Ruth Meinzen-Dick, and Peter Hazell, October 1998.

02 Assessing the Relationships between Property Rights and Technology Adoption in Smallholder Agriculture: A Review of Issues and Empirical Methods, by Frank Place and Brent Swallow, April 2000.

03 Impact of Land Tenure and Socioeconomic Factors on Mountain Terrace Maintenance in Yemen, by A. Aw-Hassan, M. Alsanabani and A. Bamatraf, July 2000 .

04 Land Tenurial Systems and the Adoption of a Mucuna Planted Fallow in the Derived Savannas of West Africa, by Victor M. Manyong and Victorin A. Houndékon, July 2000 .

05 Collective Action in Space: Assessing How Collective Action Varies Across an African Landscape, by Brent M. Swallow, Justine Wangila, Woudyalew Mulatu, Onyango Okello, and Nancy McCarthy, July 2000.

06 Land Tenure and the Adoption of Agricultural Technology in Haiti, by Glenn R. Smucker, T. Anderson White, and Michael Bannister, October 2000.

07 Collective Action in Ant Control, by Helle Munk Ravnborg, Ana Milena de la Cruz, María Del Pilar Guerrero, and Olaf Westermann, October 2000.

08 CAPRi Technical Workshop on Watershed Management Institutions: A Summary Paper, by Anna Knox and Subodh Gupta, October 2000.

09 The Role of Tenure in the Management of Trees at the Community Level: Theoretical and Empirical Analyses from Uganda and Malawi, by Frank Place and Keijiro Otsuka November 2000.

10 Collective Action and the Intensification of Cattle-Feeding Techniques a Village Case Study in Kenya's Coast Province, by Kimberly Swallow, November 2000.

11 Collective Action, Property Rights, and Devolution of Natural Resource Management: Exchange of Knowledge and Implications for Policy, by Anna Knox and Ruth Meinzen-Dick, January 2001. 
12 Land Dispute Resolution in Mozambique: Evidence and Institutions of Agroforestry Technology Adoption, by John Unruh, January 2001.

13 Between Market Failure, Policy Failure, and "Community Failure": Property Rights, Crop-Livestock Conflicts and the Adoption of Sustainable Land Use Practices in the Dry Area of Sri Lanka, by Regina Birner and Hasantha Gunaweera, March 2001.

14 Land Inheritance and Schooling in Matrilineal Societies: Evidence from Sumatra, by Agnes Quisumbing and Keijuro Otsuka, May 2001.

15 Tribes, State, and Technology Adoption in Arid Land Management, Syria, by Rae, J, Arab, G., Nordblom, T., Jani, K., and Gintzburger, G., June 2001.

16 The Effects of Scales, Flows, and Filters on Property Rights and Collective Action in Watershed Management, by Brent M. Swallow, Dennis P. Garrity, and Meine van Noordwijk, July 2001.

17 Evaluating Watershed Management Projects, by John Kerr and Kimberly Chung, August 2001.

18 Rethinking Rehabilitation: Socio-Ecology of Tanks and Water Harvesting in Rajasthan, North-West India, by Tushaar Shah and K.V.Raju, September 2001.

19 User Participation in Watershed Management and Research, by Nancy Johnson, Helle Munk Ravnborg, Olaf Westermann, and Kirsten Probst, September 2001.

20 Collective Action for Water Harvesting Irrigation in the Lerman-Chapala Basin, Mexico, by Christopher A. Scott and Paul Silva-Ochoa, October 2001.

21 Land Redistribution, Tenure Insecurity, and Intensity of Production: A Study of Farm Households in Southern Ethiopia, by Stein Holden and Hailu Yohannes, October 2001.

22 Legal Pluralism and Dynamic Property Rights, by Ruth Meinzen-Dick and Rajendra Pradhan, January 2002.

23 International Conference on Policy and Institutional Options for the Management of Rangelands in Dry Areas, by Tidiane Ngaido, Nancy McCarthy, and Monica Di Gregorio, January 2002.

24 Climatic Variablity and Cooperation in Rangeland Management: A Case Study From Niger, by Nancy McCarthy and Jean-Paul Vanderlinden, September 2002. 
25 Assessing the Factors Underlying the Differences in Group Performance:

Methodological Issues and Empirical Findings from the Highlands of Central Kenya, by Frank Place, Gatarwa Kariuki, Justine Wangila, Patti Kristjanson, Adolf Makauki, and Jessica Ndubi, November 2002.

26 The Importance of Social Capital in Colombian Rural Agro-Enterprises, by Nancy Johnson, Ruth Suarez, and Mark Lundy, November 2002.

27 Cooperation, Collective Action and Natural Resources Management in Burkina Faso: A Methodological Note, by Nancy McCarthy, Céline Dutilly-Diané, and Boureima Drabo, December 2002.

28 Understanding, Measuring and Utilizing Social Capital: Clarifying Concepts and Presenting a Field Application from India, by Anirudh Krishna, January 2003.

29 In Pursuit Of Comparable Concepts and Data, about Collective Action, by Amy Poteete And Elinor Ostrom, March 2003.

30 Methods of Consensus Building for Community Based Fisheries Management in Bangladesh and the Mekong Delta, by Parvin Sultana and Paul Thompson, May 2003.

31 Formal and Informal Systems in Support of Farmer Management of Agrobiodiversity: Some Policy Challenges to Consolidate Lessons Learned, by Marie Byström, March 2004.

32 What Do People Bring Into the Game: Experiments in the Field About Cooperation in the Commons, by Juan-Camilo Cárdenas and Elinor Ostrom, June 2004.

33 Methods for Studying Collective Action in Rural Development, by Ruth MeinzenDick, Monica Di Gregorio, and Nancy McCarthy, July 2004.

34 The Relationship between Collective Action and Intensification of Livestock Production: The Case of Northeastern Burkina Faso, by Nancy McCarthy, August 2004.

35 The Transformation of Property Rights in Kenya's Maasailand: Triggers and Motivations by Esther Mwangi, January 2005.

36 Farmers' Rights and Protection of Traditional Agricultural Knowledge, by Stephen B. Brush, January 2005. 
37 Between Conservationism, Eco-Populism and Developmentalism - Discourses in Biodiversity Policy in Thailand and Indonesia, by Heidi Wittmer and Regina Birner, January 2005.

38 Collective Action for the Conservation of On-Farm Genetic Diversity in a Center of Crop Diversity: An Assessment of the Role of Traditional Farmers' Networks, by Lone B. Badstue, Mauricio R. Bellon, Julien Berthaud, Alejandro Ramírez, Dagoberto Flores, Xóchitl Juárez, and Fabiola Ramírez, May 2005.

39 Institutional Innovations Towards Gender Equity in Agrobiodiversity Management: Collective Action in Kerala, South India, by Martina Aruna Padmanabhan, June 2005.

40 The Voracious Appetites of Public versus Private Property: A View of Intellectual Property and Biodiversity from Legal Pluralism, by Melanie G. Wiber, July 2005.

41 Who Knows, Who Cares? Determinants of Enactment, Awareness and Compliance with Community Natural Resource Management Bylaws in Uganda, by Ephraim Nkonya, John Pender, Edward Kato, Samuel Mugarura, and James Muwonge, August 2005.

42 Localizing Demand and Supply of Environmental Services: Interactions with Property Rights, Collective Action and the Welfare of the Poor, by Brent Swallow, Ruth Meinzen-Dick, and Meine von Noordjwik, September 2005.

43 Initiatives for Rural Development through Collective Action: The Case of Household Participation in Group Activities in the Highlands of Central Kenya, By Gatarwa Kariuki and Frank Place, September 2005.

44 Are There Customary Rights to Plants? An Inquiry among the Baganda (Uganda), with Special Attention to Gender, by Patricia L. Howard and Gorettie Nabanoga, October 2005.

45 On Protecting Farmers' New Varieties: New Approaches to Rights on Collective Innovations in Plant Genetic Resources by Rene Salazar, Niels P. Louwaars, and Bert Visser, January 2006.

46 Subdividing the Commons: The Politics of Property Rights Transformation in Kenya’s Maasailand, by Esther Mwangi, January 2006.

47 Biting the Bullet: How to Secure Access to Drylands Resources for Multiple Users, by Esther Mwangi and Stephan Dohrn, January 2006. 
48 Property Rights and the Management of Animal Genetic Resources, by Simon Anderson and Roberta Centonze, February 2006.

49 From the Conservation of Genetic Diversity to the Promotion of Quality Foodstuff: Can the French Model of 'Appellation d'Origine Contrôlée' be Exported? by Valérie Boisvert, April 2006.

50 Facilitating Collective Action and Enhancing Local Knowledge: A Herbal Medicine Case Study in Talaandig Communities, Philippines, by Herlina Hartanto and Cecil Valmores, April 2006.

51 Water, Women and Local Social Organization in the Western Kenya Highlands, by Elizabeth Were, Brent Swallow, and Jessica Roy, July 2006.

52 The Many Meanings of Collective Action: Lessons on Enhancing Gender Inclusion and Equity in Watershed Management, by Laura German, Hailemichael Taye, Sarah Charamila, Tesema Tolera, and Joseph Tanui, July 2006.

53 Decentralization and Environmental Conservation: Gender Effects from Participation in Joint Forest Management, by Arun Agrawal, Gautam Yadama, Raul Andrade, and Ajoy Bhattacharya, July 2006.

54 Improving the Effectiveness of Collective Action: Sharing Experiences from Community Forestry in Nepal, by Krishna P. Achyara and Popular Gentle, July 2006.

55 Groups, Networks, and Social Capital in the Philippine Communities, by Marie Godquin and Agnes R. Quisumbing, October 2006.

56 Collective Action in Plant Genetic Resources Management: Gendered Rules of Reputation, Trust and Reciprocity in Kerala, India, by Martina Aruna Padmanabhan, October 2006.

57 Gender and Local Floodplain Management Institutions--A case study from Bangladesh, by Parvin Sultana and Paul Thompson, October 2006.

58 Gender Differences in Mobilization for Collective Action: Case Studies of Villages in Northern Nigeria, by Saratu Abdulwahid, October 2006.

59 Gender, Social Capital and Information Exchange in Rural Uganda, by Enid Katungi, Svetlana Edmeades, and Melinda Smale, October 2006.

60 Rural Institutions and Producer Organizations in Imperfect Markets: Experiences from Producer Marketing Groups in Semi-Arid Eastern Kenya, by Bekele Shiferaw, Gideon Obare and Geoffrey Muricho, November 2006. 
61 Women's Collective Action and Sustainable Water Management: Case of SEWA's Water Campaign in Gujarat, India, by Smita Mishra Panda, October 2006.

62 Could Payments for Environmental Services Improve Rangeland Management inCentral Asia, West Asia and North Africa? by Celine Dutilly-Diane, Nancy McCarthy, Francis Turkelboom, Adriana Bruggeman, James Tiedemann, Kenneth Street and Gianluca Serra, January 2007. 